\title{
Impact of mush reservoir processes on the source, frequency and composition of large-scale volcanic eruptions.
}

\author{
MS. CATHERINE A. BOOTH ${ }^{1}$, MATTHEW D. JACKSON ${ }^{1}$, \\ R. STEPHEN J. SPARKS ${ }^{2}$ AND ALISON C. RUST ${ }^{2}$ \\ ${ }^{1}$ Imperial College London \\ ${ }^{2}$ University of Bristol \\ Presenting Author: c.booth17@imperial.ac.uk
}

Large-scale, caldera-forming, explosive volcanic eruptions are amongst the most hazardous natural phenomena on Earth. Here we show that the size, frequency and composition of these eruptions is controlled by processes in the deeper, long-lived, high crystallinity mush reservoirs from which magmas are sourced, rather than the shallow chambers in which magmas are stored prior to eruption.

Numerical modelling has previously shown that eruptible, low crystallinity, silicic magma layers can form within long-lived, mid-to-lower crustal mush reservoirs, created by upwards percolation of buoyant melt through the mush and melt accumulation at the top of the reservoir. The model includes repeated intrusion of basaltic sills into initially solid crust to create and grow the reservoir, transport of heat by conduction and advection, plus transport of mass and components by reactive flow of buoyant melt and compaction of the crystal mush. We extended the model to include (i) development of Rayleigh-Taylor instabilities (RTI) in the growing magma layer and (ii) brittle failure of the overlying solid crust in response to the buoyancy overpressure and rapid evacuation of the magma via dikes to occupy a shallow, ephemeral chamber prior to eruption.

Our results show that ongoing melt percolation in the mush reservoir accumulates a new magma layer after each evacuation event, with buoyancy overpressure increasing until failure causes another evacuation. The process repeats to produce episodic, large-scale eruptions. Our quantitative model predictions are consistent with observed size, frequency and composition of large magnitude explosive eruptions, demonstrating that the key controls on eruption size and style are the growth rate of the magma layer and associated RTI in the mush reservoir, the size of the mush reservoir and the rheology of the crust overlying the reservoir.

The so-called 'critical melt fraction' plays no role in controlling eruptions. Magma accumulation in mush reservoirs and its buoyancy-driven evacuation via dikes controls the size, frequency and composition of large-scale eruptions, by controlling the relative contribution of accumulated magma layer thickness and RTI amplitude to the overpressure required for evacuation: if overpressure is dominantly supplied by large layer thickness, eruptions tend to be large, infrequent and silicic, and vice-versa. 